\title{
The Relationship between Nutritional Status, Sleep Quality and Depression in Shift Workers
}

\author{
Merve Kiran ${ }^{1 *}$ and Perim Fatma Türker ${ }^{2}$ \\ ${ }^{1}$ Merve Kiran Nutrition Counseling Center, Turkey \\ ${ }^{2}$ Department of Nutrition and Dietetics, Faculty of Health Sciences, Baskent \\ University, Turkey \\ *Corresponding Author: Merve Kiran, Merve Kiran Nutrition Counseling Center, \\ Zonguldak, Turkey.
}

Received: May 23, 2020

Published: June 24, 2020

(C) All rights are reserved by Merve Kiran

and Perim Fatma Türker.

\begin{abstract}
Aim: Shift work expands globally and it has become necessary to increase productivity and provide continuously service in various sectors like industry. It has been identified as an important risk factor in the etiology of metabolic disorders and chronic diseases. The aim of this study was to investigate the association of sleep quality and depression with nutritional status of shift workers.

Methods: A total of 170 male rotating shift workers of an industrial organization aged between 20 - 55 years participated in this study. A questionnaire which consisted of demographic and lifestyle characteristics was used. Weight, height, waist and neck circumferences (WC and NC) of participants were measured, and body mass index (BMI) and waist-to-height ratio (WHtR) were also calculated. Body composition was assessed using bioelectrical impedance analysis. Sleep quality was assessed by Pittsburgh Sleep Quality Index (PSQI), while anxiety and depression were estimated through Hospital Anxiety and Depression Scale (HADS) questionnaire.

Results: The average age of participants was $40.1 \pm 6.87$ years. Among the 170 shift workers, $44.7 \%$ of them were pre-obese, and $35.3 \%$ were obese. As BMI increased, the percentages of poor sleep quality increased. There were positive correlations between PSQI score and WC, WHtR and body fat mass, and a negative correlation between total body water, which were found to be statistically significant. There was no relationship between depression and BMI, WC, WHtR and body fat mass. Participants with depressive symptoms had significantly higher prevalence of risk based on NC. HAD-D score was inversely correlated with fat free mass.

Conclusion: This study showed that pre-obesity and obesity is common in shift workers. The previously reported relationship between obesity and poor sleep quality is supported. Sleep quality get worse as WC, WHtR and body fat mass increase, while total body water decrease. Decrease in fat free mass is associated with the development of depressive symptoms. These associations need to be verified in large studies. Based on the results, appropriate strategies including both employer and worker should be performed to reduce the detrimental health outcomes associated with shift work.

Keywords: Shift Work; Nutritional Status; Obesity; Sleep Quality; Anxiety; Depression
\end{abstract}

\section{Introduction}

Shift work has become inevitable due to progressive globalization and industrialization, to increase productivity and provide continuously service in various sectors like industry, tourism, communication, health care, and transportation which have to work during 24-hour day [1,2]. Shift work pattern is prevalent throughout the world, accounting for $20 \%$ entire working population [3]. In Turkey, it was estimated to account for $8 \%$ of the workforce [4]. While this work system promotes productivity and sustains 24-hours services, it has been identified as an important risk factor in the etiology of metabolic disorders and chronic diseases. Compared to day time workers, increased risk of obesity, type II diabetes, cardiovascular disease, gastrointestinal disorders, sleep disorders, depression and vitamin D deficiency have been reported among shift workers $[1-3,5,6]$.

Shift work can affect health primarily through two mechanisms; the lifestyle and the pathophysiology [7]. Due to the reorganization 
of day time and night-time activities, changes in lifestyle can affect eating habits in many aspects including changes in meal frequency, types of meals and times for meals [8]. The deteriorating of lifestyles related to increased sedentary and poor eating habits influences the obesity risk [7]. Previous studies have shown that overweight and obesity are more prevalent in shift workers than day workers [9-13]. Pathophysiology is related to disruption of circadian rhythm and increased oxidative stress [7]. When the circadian rhythm does not match the sleep-wake cycle, as seen in shift workers, it causes circadian desynchrony leading to sleep disturbances in both aspects of quantity and quality. Shift workers commonly experience sleep restriction according to circadian desynchrony, the timing of shifts and rest periods and the environmental influences [14]. The association of shift work with poor sleep quality is also well documented [15-18].

Shift work also has effects on the mental health. Sleep deficits and persistent disruption of circadian rhythm have been associated with irritability, depressed mood, anxiety, and nervousness [19]. Some studies reported increased risks of anxiety and depression in shift workers $[10,15,18]$. A meta-analysis has suggested that night shift work is associated with the increased risk of depression [20].

Although previous researchers have identified an effect of shift work on obesity, sleep quality and as well as depression, studies examining the associations between other anthropometric measurements and sleep quality and depression in relation to shift work are scarce.

\section{Aim of the Study}

The current study aimed to investigate the association of sleep quality and depression with obesity and specific anthropometric measurements in shift workers.

\section{Materials and Methods}

Study design

This cross-sectional study was carried out with 170 male rotating shift workers of an industrial organization aged between 20 - 55 years who volunteered to participate in the study between March and June 2019. A written informed consent was obtained from all participants as to their voluntary participation.

The exclusion criteria were being female and having chronic diseases needed nutritional intervention.
This study was obtained by doctoral thesis which was approved by Baskent University Institutional Review Board and Ethics Committee (Project no: KA19/65).

\section{Study variables and measurements}

\section{General characteristics}

Information about demographic and lifestyle characteristics including age, marital status, education level, shift work experience, alcohol consumption, smoking status and physical activity level was gathered by a questionnaire. The questionnaire was administered by the researcher with face-to-face interviews.

The age range was 20 - 55 years and the participants were divided into three groups: 20 - 30, 31 - 40 and 41 years and older. Marital status was classified as married or single/divorced. Education data were categorized as junior high school, high school and university. The length of shift work experience were categorized as $<5$ years, 5 - 10 years or $\geq 10$ years for each variable. For smoking, the subjects were classified as non-smokers, ex-smokers, and current-smokers. Workers' alcohol consumption was classified whether they drink or not. Last, according to physical activity level (PAL), the participants were categorized as light (1.40 - 1.69), moderate (1.70 - 1.99) and vigorous (2.00 - 2.40) [21].

\section{Anthropometric measurements}

Body weight and height measurements were performed without shoes and with light clothing in a standing position. To ensure accurate height measurements, participants were asked to keep their feet side-by-side and heads' were adjusted to the Frankfurt horizontal plane. Body Mass Index was calculated [BMI=weight (kg)/ height $\left.(\mathrm{m})^{2}\right]$ and categorized according to World Health Organization criteria as normal weight (18.5 - $\left.24.9 \mathrm{~kg} / \mathrm{m}^{2}\right)$, pre-obese(25.0 - $\left.29.9 \mathrm{~kg} / \mathrm{m}^{2}\right)$, or obese $\left(\geq 30.0 \mathrm{~kg} / \mathrm{m}^{2}\right)[22]$.

Waist circumference (WC) was measured using an inelastic measuring tape, at a horizontal plane midway between the lowest rib and the iliac crest. Participants with a $\mathrm{WC}<94 \mathrm{~cm}$ were classified as normal; participants with a WC $\geq 94 \mathrm{~cm}$ were classified as increased risk; and those with a WC $\geq 102 \mathrm{~cm}$ were classified as substantially increased risk [23].

Waist-to-height ratio (WHtR) was calculated by dividing WC to height. WHtR was classified as the following boundary values: no increased risk $(\mathrm{WHtR}<0.5)$, increased risk $(\mathrm{WHtR} \geq 0.5$ and $<0.6)$ and very high risk $(W H t R \geq 0.6)[24]$. 
Neck circumference (NC) was also measured using an inelastic measuring tape which was positioned just below the top edge of the laryngeal prominence. Cutoff value was set at $\geq 37 \mathrm{~cm}[25]$.

Body composition was assessed using bioelectrical impedance analysis (Tanita BC-418) and was differentiated into fat mass (FM), fat-free mass (FFM), body fat ratio, and total body water. During the measurement, the feet were placed naked and dry, corresponding to the electrodes on the device. Heavy physical exercise was restricted 24 hours before the measurement.

\section{Sleep quality}

Sleep quality was assessed according to the Pittsburgh Sleep Quality Index, PSQI. The PSQI is a self-rated questionnaire assessing sleep quality and impairment over the past month. It is composed of nineteen items that generate seven component scores (range 0 - 3, with higher scores indicating worse sleep) on subjective sleep quality, sleep latency, sleep duration, habitual sleep efficiency, sleep disturbances, use of sleeping medication, and daytime dysfunction. Each component is then summed up to produce an overall score from 0 to 21 . Participants with PSQI $\leq 5$ were classified as good sleepers, while participants with PSQI $>5$ were classified as poor sleepers [26]. In Turkey, the validity and reliability study of PSQI was assessed by Ağargün., et al [27].

\section{Anxiety and depression status}

Hospital Anxiety and Depression Scale (HADS) were used to measure anxiety and depression levels of the participants. HADS is a self-reported fourteen-item questionnaire. It is composed of two seven-item subscales; one measuring anxiety (HAD-A) and one depression (HAD-D), which are scored separately. Each item is answered on a four point ( 0 - 3) Likert scale, so possible scores range from 0 to 21 . The cut-off point is determined 10 for anxiety, and 7 for depression which means anxiety is mentioned when the HAD-A score $\geq 11$, and depression is mentioned when the HAD-D score $\geq 8$ [28]. The validity and reliability study of HADS was assessed by Aydemir., et al. in Turkey [29].

\section{Statistical analyses}

All statistical analyses were performed using IBM SPSS Statistics Version 22.0. The level of statistical significance was considered as $\mathrm{p}<0.05$. Data were presented as means and standard deviations (SD) for continuous variables and as frequencies and percentages for categorical variables. Chi-square test was used for the comparison of categorical variables. The variables were investigated with Kolmogorov-Simirnov test to determine whether or not they are normally distributed. Student-t test was used for the parameters which have normal distribution in the comparisons between groups. Mann-Whitney $U$ test was used to test differences of non-normal distribution of the variables between groups. While investigating the associations between variables, the correlation coefficients and their significance were calculated by using Spearman correlation test.

\section{Results}

This study was conducted on 170 male rotating shift workers. The majority (51.8\%) was at the age of 41 years and older. The average age of participants was $40.1 \pm 6.87$ years. Among the 170 participants, 104 (61.2\%) had good sleep quality and 66 (38.8\%) had poor sleep quality. Of the individuals with poor sleep quality, 83.3 $\%$ had a shift working period comprising of ten years and above. No significant differences in terms of lifestyle behaviors (smoking status, alcohol consumption, physical activity level) between two qualities of sleep were observed. The mean score for anxiety was $6.5 \pm 3.38$ and for depression was $5.5 \pm 3.39$. According to the categorization of risk status, $7.6 \%$ of the participants had anxiety symptoms and $25.9 \%$ had depressive symptoms. When shift working period was considered, the prevalence of anxiety and depression among the subjects worked at least ten years was $76.9 \%$ and $75.0 \%$, respectively, but the difference was not statistically significant. Also, the prevalence of both anxiety and depression was highest among the subjects having light physical activity level (69.2\% and $59.1 \%$ respectively), but the difference was not statistically significant, too. Education level and alcohol consumption showed statistically significant relationships with depression (Table 1).

According to BMI classification of WHO, 44.7\% of shift workers were pre-obese, and $35.3 \%$ of them were obese. The majority was at substantially increased risk based on WC and very high risk based on WHtR (55.9\% and $44.7 \%$ respectively). Only $9.4 \%$ of participants were not at risk assessing by NC classification.

As BMI increased, the percentages of poor sleep quality increased. Groups did not differ in WC and WHtR in terms of sleep quality and anxiety and depression status. Shift workers in depression group had significantly higher prevalence of risk based on NC (Table 2). 
The Relationship between Nutritional Status, Sleep Quality and Depression in Shift Workers

68

\begin{tabular}{|c|c|c|c|c|c|c|c|c|c|c|c|c|c|c|c|c|c|}
\hline \multirow{3}{*}{\begin{tabular}{|c|}
$\begin{array}{c}\text { Socio } \\
\text { demographic } \\
\text { Characteristics }\end{array}$ \\
Age groups (years)
\end{tabular}} & \multicolumn{4}{|c|}{ Sleep quality } & \multirow{6}{*}{\begin{tabular}{|c|}
$\boldsymbol{P}$ \\
0.079 \\
\end{tabular}} & \multicolumn{4}{|c|}{ Anxiety } & \multirow{3}{*}{\begin{tabular}{|c|}
$\boldsymbol{P}$ \\
0.640 \\
\end{tabular}} & \multicolumn{4}{|c|}{ Depression } & \multirow{3}{*}{\begin{tabular}{|c|}
$\boldsymbol{P}$ \\
0.336 \\
\end{tabular}} & \multirow{2}{*}{\multicolumn{2}{|c|}{$\begin{array}{l}\text { Total } \\
(\mathbf{n}= \\
\mathbf{1 7 0})\end{array}$}} \\
\hline & \multicolumn{2}{|c|}{$\begin{array}{c}\text { Good sleep } \\
\text { quality } \\
(\mathbf{n}=104)\end{array}$} & \multicolumn{2}{|c|}{$\begin{array}{c}\text { Poor sleep } \\
\text { quality } \\
(n=66)\end{array}$} & & \multicolumn{2}{|c|}{$\begin{array}{c}\text { No } \\
\text { anxiety } \\
(n=157)\end{array}$} & \multicolumn{2}{|c|}{$\begin{array}{c}\text { Diseased } \\
(n=13)\end{array}$} & & \multicolumn{2}{|c|}{$\begin{array}{c}\text { No } \\
\text { depression } \\
(\mathrm{n}=126)\end{array}$} & \multicolumn{2}{|c|}{$\begin{array}{c}\text { Diseased } \\
(n=44)\end{array}$} & & & \\
\hline & $\mathrm{N}$ & $\%$ & $\mathrm{~N}$ & $\%$ & & $\mathrm{~N}$ & $\%$ & $\mathrm{~N}$ & $\%$ & & $\mathrm{~N}$ & $\%$ & $\mathrm{~N}$ & $\%$ & & $\mathrm{~N}$ & $\%$ \\
\hline $20-30$ & 11 & 10.6 & 8 & 12.1 & & 17 & 10.8 & 2 & 15.4 & & 12 & 9.5 & 7 & 15.9 & & 19 & 11.2 \\
\hline $31-40$ & 37 & 35.5 & 26 & 39.4 & & 57 & 36.3 & 6 & 46.2 & & 50 & 39.7 & 13 & 29.5 & & 63 & 37.1 \\
\hline 41 and older & 56 & 53.8 & 32 & 48.5 & & 83 & 52.9 & 5 & 38.5 & & 64 & 50.8 & 24 & 54.5 & & 88 & 51.8 \\
\hline Mean \pm SD & \multicolumn{2}{|c|}{$40.1 \pm 7.25$} & \multicolumn{2}{|c|}{$40.1 \pm 6.29$} & 0.640 & \multicolumn{2}{|c|}{$40.2 \pm 6.89$} & \multicolumn{2}{|c|}{$39.1 \pm 6.82$} & 0.500 & \multicolumn{2}{|c|}{$40.1 \pm 6.94$} & \multicolumn{2}{|c|}{$40.2 \pm 6.77$} & 0.730 & \multicolumn{2}{|c|}{$40.1 \pm 6.87$} \\
\hline \multicolumn{18}{|l|}{ Marital status } \\
\hline Married & 84 & 80.8 & 55 & 83.3 & \multirow[t]{2}{*}{0.673} & 129 & 82.2 & 10 & 76.9 & \multirow[t]{2}{*}{0.708} & 105 & 83.3 & 34 & 77.3 & \multirow[t]{2}{*}{0.370} & 139 & 81.8 \\
\hline Single/divorced & 20 & 19.2 & 11 & 16.7 & & 28 & 17.8 & 3 & 23.1 & & 21 & 16.7 & 10 & 22.7 & & 31 & 18.2 \\
\hline Education level & & & & & & & & & & & & & & & & & \\
\hline Junior high school & 8 & 7.7 & 1 & 1.5 & 0.177 & 9 & 5.7 & 0 & 0 & 0.781 & 4 & 3.2 & 5 & 11.4 & $0.016^{*}$ & 9 & 5.3 \\
\hline High school & 68 & 65.4 & 43 & 65.2 & & 103 & 65.6 & 8 & 61.5 & & 79 & 62.7 & 32 & 72.7 & & 111 & 65.3 \\
\hline University & 28 & 26.9 & 22 & 33.3 & & 45 & 28.7 & 5 & 38.5 & & 43 & 34.1 & 7 & 15.9 & & 50 & 29.4 \\
\hline $\begin{array}{l}\text { Shift working } \\
\text { period (years) }\end{array}$ & & & & & & & & & & & & & & & & & \\
\hline$\leq 5$ & 19 & 18.3 & 10 & 15.2 & $0.040^{*}$ & 26 & 16.6 & 3 & 23.1 & 0.597 & 22 & 17.5 & 7 & 15.9 & 0.901 & 29 & 17.1 \\
\hline $5-10$ & 12 & 11.5 & 1 & 1.5 & & 13 & 8.3 & 0 & 0.0 & & 9 & 7.1 & 4 & 9.1 & & 13 & 7.6 \\
\hline$\geq 10$ & 73 & 70.2 & 55 & 83.3 & & 118 & 75.2 & 10 & 76.9 & & 95 & 75.4 & 33 & 75.0 & & 128 & 75.3 \\
\hline $\begin{array}{l}\text { Lifestyle } \\
\text { Behaviors }\end{array}$ & & & & & & & & & & & & & & & & & \\
\hline Smoking status & & & & & & & & & & & & & & & & & \\
\hline Non-smoker & 43 & 41.3 & 16 & 24.2 & 0.074 & 56 & 35.7 & 3 & 23.1 & 0.480 & 46 & 36.5 & 13 & 29.5 & 0.106 & 59 & 34.7 \\
\hline Ex-smoker & 13 & 12.5 & 11 & 16.7 & & 21 & 13.4 & 3 & 23.1 & & 21 & 16.7 & 3 & 6.8 & & 24 & 14.1 \\
\hline Current-smoker & 48 & 46.2 & 39 & 59.1 & & 80 & 51.0 & 7 & 53.8 & & 59 & 46.8 & 28 & 63.6 & & 87 & 51.2 \\
\hline $\begin{array}{l}\text { Alcohol } \\
\text { consumption }\end{array}$ & & & & & & & & & & & & & & & & & \\
\hline No & 66 & 63.5 & 39 & 59.1 & 0.568 & 96 & 61.1 & 9 & 69.2 & 0.768 & 71 & 56.3 & 34 & 77.3 & $0.014^{*}$ & 105 & 61.8 \\
\hline Yes & 38 & 36.5 & 27 & 40.9 & & 61 & 38.9 & 4 & 30.8 & & 55 & 43.7 & 10 & 22.7 & & 65 & 38.2 \\
\hline $\begin{array}{l}\text { Physical activity } \\
\text { level }\end{array}$ & & & & & & & & & & & & & & & & & \\
\hline Light & 51 & 49.0 & 37 & 56.1 & 0.698 & 79 & 50.3 & 9 & 69.2 & 0.262 & 62 & 49.2 & 26 & 59.1 & 0.202 & 88 & 51.8 \\
\hline Moderate & 48 & 46.2 & 27 & 40.9 & & 72 & 45.9 & 3 & 23.1 & & 57 & 45.2 & 18 & 40.9 & & 75 & 44.1 \\
\hline Vigorous & 5 & 4.8 & 2 & 3.0 & & 6 & 3.8 & 1 & 7.7 & & 7 & 5.6 & 0 & 0.0 & & 7 & 4.1 \\
\hline
\end{tabular}

Table 1: General characteristics of the subjects according to their sleep quality and anxiety and depression status. 


\begin{tabular}{|c|c|c|c|c|c|c|c|c|c|c|c|c|c|c|c|c|c|}
\hline \multirow{3}{*}{\begin{tabular}{|c|}
$\begin{array}{c}\text { Anthropometric } \\
\text { measurements }\end{array}$ \\
$\mathrm{BMI}\left(\mathrm{kg} / \mathrm{m}^{2}\right)$ \\
\end{tabular}} & \multicolumn{4}{|c|}{ Sleep quality } & \multirow{3}{*}{\begin{tabular}{|c|}
$\boldsymbol{p}$ \\
$0.040^{*}$
\end{tabular}} & \multicolumn{4}{|c|}{ Anxiety } & \multirow{3}{*}{\begin{tabular}{|c|}
$p$ \\
0.197 \\
\end{tabular}} & \multicolumn{4}{|c|}{ Depression } & \multirow{3}{*}{\begin{tabular}{|c|}
$p$ \\
0.396 \\
\end{tabular}} & \multirow{2}{*}{\multicolumn{2}{|c|}{$\begin{array}{c}\text { Total } \\
(n=170)\end{array}$}} \\
\hline & \multicolumn{2}{|c|}{$\begin{array}{c}\text { Good sleep } \\
\text { quality } \\
(\mathrm{n}=104)\end{array}$} & \multicolumn{2}{|c|}{$\begin{array}{c}\text { Poor sleep } \\
\text { quality } \\
(\mathrm{n}=66)\end{array}$} & & \multicolumn{2}{|c|}{$\begin{array}{c}\text { No } \\
\text { anxiety } \\
(\mathrm{n}=157)\end{array}$} & \multicolumn{2}{|c|}{$\begin{array}{c}\text { Diseased } \\
(n=13)\end{array}$} & & \multicolumn{2}{|c|}{$\begin{array}{c}\text { No de- } \\
\text { pression } \\
(n=126)\end{array}$} & \multicolumn{2}{|c|}{$\begin{array}{c}\text { Diseased } \\
(n=44)\end{array}$} & & & \\
\hline & $\mathrm{N}$ & $\%$ & $\mathrm{~N}$ & $\%$ & & $\mathrm{~N}$ & $\%$ & $\mathrm{~N}$ & $\%$ & & $\mathrm{~N}$ & $\%$ & $\mathrm{~N}$ & $\%$ & & $\mathrm{~N}$ & $\%$ \\
\hline Normal weight & 23 & 22.1 & 11 & 16.7 & & 31 & 19.7 & 3 & 23.1 & & 23 & 18.3 & 11 & 25 & & 34 & 20.0 \\
\hline Pre-obesity & 52 & 50.0 & 24 & 36.4 & & 73 & 46.5 & 3 & 23.1 & & 60 & 47.6 & 16 & 36.4 & & 76 & 44.7 \\
\hline Obesity & 29 & 27.9 & 31 & 47.0 & & 53 & 33.8 & 7 & 53.8 & & 43 & 34.1 & 43 & 34.1 & & 60 & 35.3 \\
\hline \multicolumn{18}{|l|}{$\begin{array}{l}\text { Waist circumference } \\
\text { (cm) }\end{array}$} \\
\hline Normal & 23 & 22.1 & 11 & 16.7 & \multirow[t]{3}{*}{0.268} & 31 & 19.7 & 3 & 23.1 & \multirow[t]{3}{*}{0.418} & 23 & 18.3 & 11 & 25.0 & \multirow[t]{3}{*}{0.445} & 34 & 20.0 \\
\hline Increased risk & 28 & 26.9 & 13 & 19.7 & & 40 & 25.5 & 1 & 7.7 & & 33 & 26.2 & 8 & 18.2 & & 41 & 24.1 \\
\hline $\begin{array}{l}\text { Substantially increased } \\
\text { risk }\end{array}$ & 53 & 51.0 & 42 & 63.6 & & 86 & 54.8 & 9 & 69.2 & & 70 & 55.6 & 25 & 56.8 & & 95 & 55.9 \\
\hline \multicolumn{18}{|l|}{ Waist to height ratio } \\
\hline No increased risk & 15 & 14.4 & 5 & 7.6 & \multirow[t]{3}{*}{0.157} & 19 & 12.1 & 1 & 7.7 & \multirow[t]{3}{*}{0.200} & 13 & 6.3 & 7 & 15.9 & \multirow[t]{3}{*}{0.293} & 20 & 11.8 \\
\hline Increased risk & 48 & 46.2 & 26 & 39.4 & & 71 & 45.2 & 3 & 23.1 & & 59 & 46.8 & 15 & 34.1 & & 74 & 43.5 \\
\hline Very high risk & 41 & 39.4 & 35 & 53.0 & & 67 & 42.7 & 9 & 69.2 & & 54 & 42.9 & 22 & 50.0 & & 76 & 44.7 \\
\hline \multicolumn{18}{|l|}{$\begin{array}{l}\text { Neck circumference } \\
(\mathrm{cm})\end{array}$} \\
\hline Normal & 10 & 9.6 & 6 & 9.1 & \multirow[t]{2}{*}{0.909} & 14 & 8.9 & 2 & 15.4 & \multirow[t]{2}{*}{0.352} & 8 & 6.3 & 8 & 18.2 & \multirow[t]{2}{*}{$0.033^{*}$} & 16 & 9.4 \\
\hline Risk & 94 & 90.4 & 60 & 90.9 & & 143 & 91.1 & 11 & 84.6 & & 118 & 93.7 & 36 & 81.8 & & 154 & 90.6 \\
\hline
\end{tabular}

Table 2: The BMIs, waist circumference, waist to height ratio, and neck circumferences of the subjects according to their sleep quality and anxiety and depression status.

Means of all body weight, BMI, WC, NC, body fat ratio, body fat mass and fat free mass were higher in the participants with poor sleep quality compared to those with good sleep quality and in the anxiety groups compared to the non-anxiety ones. But only the difference in NC between poor and good sleepers was statistically significant. Although, total body water ratio was higher in the groups of good sleep quality, anxiety and depression compared to corresponding groups, these differences were not statistically significant (Table 3).

Sleep quality was determined to get worse as body weight, BMI, WC, WHtR, NC, body fat ratio and body fat mass increased. These WC, WHtR and body fat mass related increase in PSQI score was found to be statistically significant. There was a significant negative correlation between PSQI score and total body water.
Although, there were positive correlations between HAD-A score and body weight, BMI, WC, WHtR, NC, body fat ratio, body fat mass, these were not statistically significant. HAD-D score was inversely correlated with fat free mass. As the number of the years of shift work experience increased, body weight, BMI, WC, WHtR, $\mathrm{NC}$, body fat ratio and body fat mass increased. There was also a significant negative correlation between shift working period and total body water ratio.

\section{Discussion}

This study aimed to investigate the associations between nutritional status and sleep quality and depression in an industrial shift working population. Results have shown that pre-obesity and obesity is common in shift workers. Previous studies were in good agreement to demonstrate that shift workers are more overweight 
The Relationship between Nutritional Status, Sleep Quality and Depression in Shift Workers

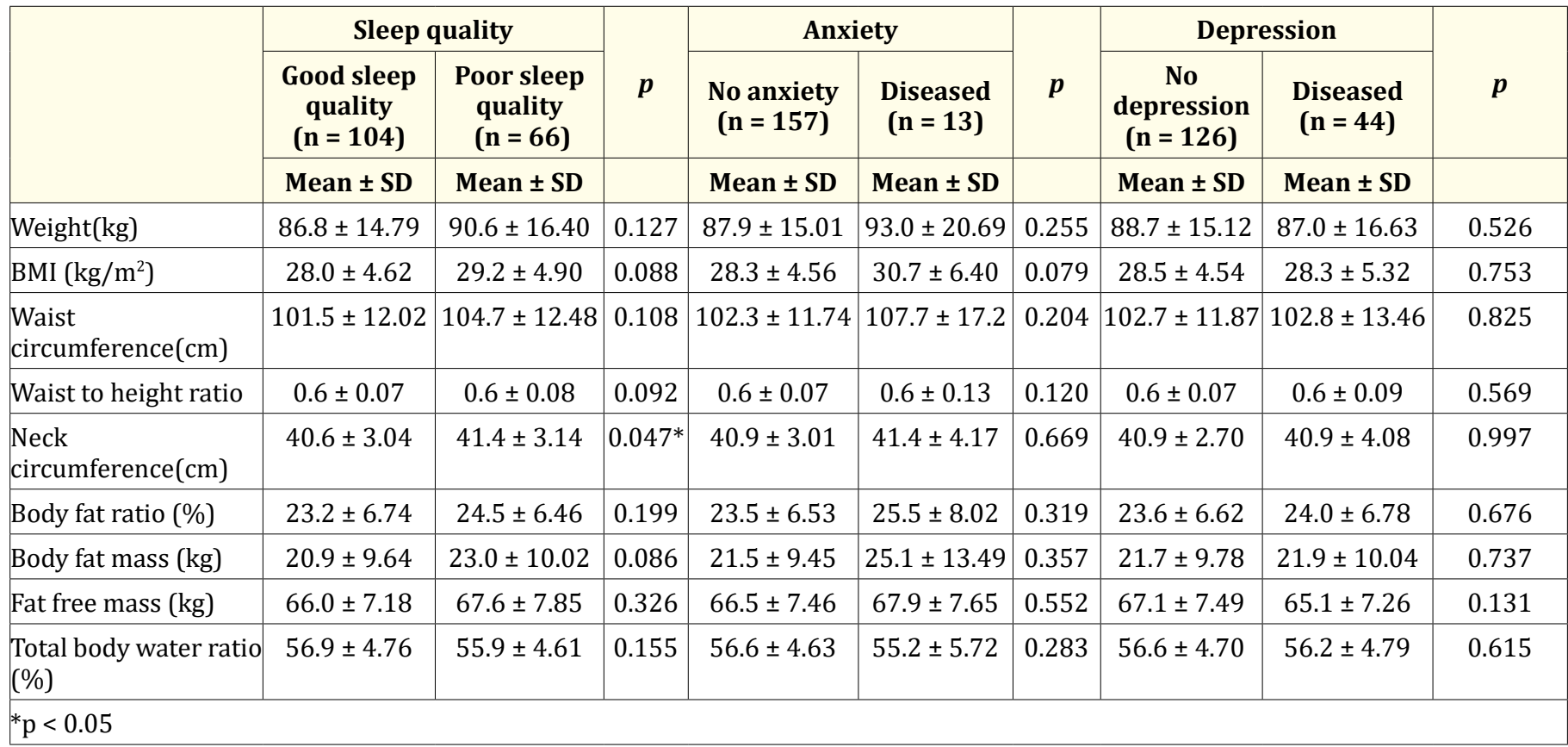

Table 3: The anthropometric measurements of the subjects according to their sleep quality and anxiety and depression status.

\begin{tabular}{|c|c|c|c|c|c|}
\hline & & PSQI Score & HAD-A Score & HAD-D Score & Shift working period \\
\hline \multirow{2}{*}{ Weight(kg) } & $\mathrm{r}$ & 0.124 & 0.066 & -0.052 & 0.269 \\
\hline & $\mathrm{p}$ & 0.106 & 0.395 & 0.502 & $0.000^{*}$ \\
\hline \multirow{2}{*}{$\mathrm{BMI}\left(\mathrm{kg} / \mathrm{m}^{2}\right)$} & $\mathrm{r}$ & 0.144 & 0.091 & -0.004 & 0.390 \\
\hline & $\mathrm{p}$ & 0.060 & 0.236 & 0.958 & $0.000^{*}$ \\
\hline \multirow{2}{*}{ Waist circumference $(\mathrm{cm})$} & $\mathrm{r}$ & 0.157 & 0.108 & -0.022 & 0.336 \\
\hline & $\mathrm{p}$ & $0.040^{*}$ & 0.163 & 0.774 & $0.000^{*}$ \\
\hline \multirow{2}{*}{ Waist to height ratio } & $\mathrm{r}$ & 0.159 & 0.117 & 0.017 & 0.383 \\
\hline & $\mathrm{p}$ & $0.038^{*}$ & 0.129 & 0.824 & $0.000^{*}$ \\
\hline \multirow{2}{*}{ Neck circumference $(\mathrm{cm})$} & $\mathrm{r}$ & 0.138 & 0.080 & 0.022 & 0.358 \\
\hline & $\mathrm{p}$ & 0.073 & 0.300 & 0.780 & $0.000^{*}$ \\
\hline \multirow{2}{*}{ Body fat ratio (\%) } & $\mathrm{r}$ & 0.145 & 0.095 & 0.080 & 0.377 \\
\hline & $\mathrm{p}$ & 0.059 & 0.216 & 0.301 & $0.000^{*}$ \\
\hline \multirow{2}{*}{ Body fat mass(kg) } & $\mathrm{r}$ & 0.152 & 0.097 & 0.040 & 0.354 \\
\hline & $\mathrm{p}$ & $0.048^{*}$ & 0.206 & 0.606 & $0.000^{*}$ \\
\hline \multirow{2}{*}{ Fat free mass $(\mathrm{kg})$} & $\mathrm{r}$ & 0.082 & 0.016 & -0.155 & 0.126 \\
\hline & $\mathrm{p}$ & 0.287 & 0.831 & $0.043^{*}$ & 0.102 \\
\hline \multirow{2}{*}{ Total body water (\%) } & $\mathrm{r}$ & -0.152 & -0.103 & -0.077 & -0.360 \\
\hline & $\mathrm{p}$ & $0.047^{*}$ & 0.182 & 0.319 & $0.000^{*}$ \\
\hline & & $* \mathrm{p}<0.05$ & & & \\
\hline
\end{tabular}

Table 4: Correlation between PSQI, HAD-A, HAD-D Scores, shift working period and anthropometric measurements. 
and obese than those who do not work in shifts [9-13]. In a longitudinal study of Iranian petrochemical industries staff, it was found that the odds of being overweight or obese in shift workers was about $18 \%$ higher than the day workers [30]. Grundy., et al. found rotating shift work is also associated with an increased risk of being overweight or obese in a study of 1561 men [31]. Cohort studies, that examined the association between shift work and obesity, were all agreed that night-time use is an important health risk factor for weight gain and/or BMI increase [2,10,11].

The effects of shift work on abdominal obesity, which is the trigger for the development of further metabolic disorders have also been demonstrated [32]. A systematic review and meta-analysis investigating the associations between shift work patterns and risks of specific types of obesity showed that night-shift work was associated with a $23 \%$ increased risk of obesity compared to daytime shift work, and the increased risk of abdominal obesity was even greater at 35\% [3]. According to findings of the Atlantic PATH cohort study, shift workers had higher BMI, WC, and fat mass index compared to non-shift workers [9]. These findings are consistent with another cohort study, UK Biobank study, which showed that shift workers had higher BMI, WC, and body fat percentage than non-shift workers [10]. Additionally, in a cross-sectional study of approximately 35000 Brazilian shift workers, individuals who worked two or more nights a week had higher odds of overweight, obesity and increased WC than daytime workers [12]. A Turkish cross-sectional study also showed that shift working security guards had higher BMI and WC compared to day time workers [13]. In parallel with these results, the current study revealed a high prevalence of abdominal obesity (55.9\%) among shift workers.

In our study, we also found that body weight, BMI, WC, WHtR, $\mathrm{NC}$, body fat ratio and body fat mass increased with the number of years of shift work. Similarly, several studies demonstrated that night shift work contributes to an increase in BMI and WC and to gain weight [33-35]. It was also observed a trend of increasing risk of overweight and/or obesity with increasing duration of rotating shift work [31]. In a study conducted in Korean nurses, it was found that the nurses with the longest duration of shift work had a 1.63 times greater risk of overweight/obesity when the shortest duration of shift work was used as a reference [36]. A cross-sectional study, which was carried out with 2100 nurses, suggested that the number of the years of night shift exposure was related to BMI increases [37]. Samhat., et al. also found that BMI and WC increased with the number of years of work and cumulative night shift hours over the entire work history [34].

The association between night shift work exposure and the development of obesity can be explained by several mechanisms. One of the key potential mechanisms has been considered as circadian disruption. Circadian disruption is a consequence of exposure to artificial light during their night working period, which may lead to suppression of melatonin secretion. Melatonin plays an important role in synchronizing central and peripheral circadian rhythms and regulates the secretion of hormones such as cortisol, insulin and leptin. Such misalignments may disrupt the balance of energy metabolism, reducing resting metabolism, resulting in weight gain and an increased risk for obesity [3]. Furthermore, the modification of lifestyle habits, especially in point of timing and quality of meals, affects the risk of obesity. Shift workers tend to have more irregular eating patterns [7]. Samhat., et al. confirmed that excessive snacking during night and consumption of high-fat and high sugar foods were common among night shift nurses [34]. Decreased physical activity is regarded another important factor that has been linked to weight gain and obesity among shift workers [7]. Due to work schedules and sleep deprivation, they might have limited opportunity for physical activity. In a review, conducted by Flahr., et al. concluded that many shift workers were insufficiently active and fail to achieve the recommended physical activity guidelines [38]. According to the results of the current study, the majority of participants had also low physical activity levels.

Sleep deprivation is another significant mechanism which is responsible for weight gain in shift workers. The short duration of sleep decreases leptin and increases ghrelin resulting in greater appetite and weight gain. In this context, the reduction in the number of hours of sleep may be related to the increased incidence of obesity and overweight [39]. The desynchronization of rhythmic physiological functions also impairs sleep quality which involves both quantitative and qualitative aspects and it may eventually play a role in increasing the incidence of obesity $[39,40]$. Sleep quality has also been negatively affected by social factors like financial stress, health concerns, and an unfavorable work schedule (e.g. working the night shift) [41]. The relatively high prevalence of good sleep quality among shift workers in our study may be due to less ex- 
posure to these factors considering that they all work in rotating shifts, including morning shifts, not only in night shifts. The association of shift work with poor sleep quality is well documented in the literature [15-18]. Our study found that as BMI increased, the percentage of poor sleep quality increased. These results are consistent with other research findings. For example, Abbasi., et al. found high BMI was associated with poor sleep quality in firefighters whose job also require shift work [42]. In a study of nurses, it was found that BMI and sleep quality were significantly associated [43]. The current study revealed that as WC, WHtR and body fat mass increased, PSQI score increased. On the other hand, there was a negative correlation between PSQI score and total body water. Rahe., et al. investigated the association between sleep quality and different measures of obesity such as general obesity, abdominal obesity and body composition in the Germanic population and they found a significant association of poorer sleep quality with general obesity and high body fat mass in adults [44]. Similarly, in a study of Caucasian adults, it was reported that PSQI score was related significantly to WC, BMI and percentage of body fat [45]. Unlike previous findings, in Turkey, Çatırtan and Bakır did not find any difference in BMI and wc according to shift status and sleep quality [46]. In a recent meta-analysis, it was showed that lower BMI was associated with higher prevalence of poor sleep quality and it was indicated that this unexpected finding needs to be reexamined in future studies [47]. Neck circumference, another anthropometric measurement of obesity, was considered as a strong predictor of sleep disorders [44]. Our study's findings corroborate this by showing that shift workers with poor sleep quality had significantly larger NC.

Shift work also has effects on the mental health. Altered sleep patterns and disruption of circadian rhythm have been associated with irritability, depressed mood, anxiety, and nervousness [19]. Some studies reported increased risks of anxiety and depression in shift workers $[10,15,18]$. The results of a meta-analysis of longitudinal studies showed that shift work was associated with an increased overall risk of adverse mental health outcomes combined and it was found that the risk of depressive symptoms was $33 \%$ higher in shift workers than in non-shift workers [19]. Another meta-analysis suggested that night shift work was associated with the increased risk of depression [20]. In the current study, 7.6\% of the shift workers had anxiety symptoms and $25.9 \%$ had depres- sion symptoms. Compared to other studies of shift workers that conducted in Turkey, the prevalence of both anxiety and depression was lower in our study $[48,49]$. Although some controversies, there are numerous data that link obesity to anxiety and depressive symptoms [50]. In our study, there was no relationship between BMI, WC and WHtR and anxiety and depressive symptoms. Shift workers with depressive symptoms had significantly higher prevalence of risk based on NC. Besides, a recent study indicated the BMI-depression causality was driven by fat. It was found that body fat mass was a causal risk factor for depression, but that body nonfat mass was not [51]. In the current study, there was a negative correlation between fat free mass and depressive symptoms. Our study's findings corroborate those of Guedes., et al. who found that total lean mass was strongly associated with fewer anxiety and depressive symptoms [52].

The major strength of the present study is assessment of different anthropometric measurements, including waist circumference, neck circumference and body composition instead of only BMI in terms of sleep quality and depression. However, it should be noted that, due to the cross-sectional design of the study, it is not possible to determine the causal relationships between shift work and obesity, sleep quality and depression. Therefore, more extensive studies are needed in this topic.

\section{Conclusion}

This study shows that pre-obesity and obesity is common in shift workers. The previously reported relationship between obesity and poor sleep quality is supported. Sleep quality get worse as waist circumference, waist-to-height ratio and body fat mass increase, while total body water decrease. Decrease in fat free mass is associated with the development of depressive symptoms. Due to low number of studies investigating the relationship between shift work and sleep quality and depression in terms of anthropometric measurements excluding BMI and inconsistency in study findings led to insufficient evidence with respect to the relation between nutritional status of shift workers and sleep quality and depression. To strengthen the evidence, more studies are needed. Considering that shift work is expanding globally and become a necessary component of many occupations, to reduce the detrimental health outcomes associated with shift work, appropriate strategies including both employer and worker should be performed. 


\section{Bibliography}

1. Costa G. "Shift work and health: current problems and preventive actions". Safety Health Work 1.2 (2010): 112-123.

2. Suwazono Y., et al. "A longitudinal study on the effect of shift work on weight gain in male Japanese workers". Obesity 16.8 (2008):1887-1893.

3. Sun M., et al. "Meta-analysis on shift work and risks of specific obesity types". Obesity Reviews 19.1 (2018): 28-40.

4. Y Ylldız AN., et al. "Vardiyalı Çalışmalarda Iş̧ Sağlığı ve Güvenliği Konuları". Aydoğdu Ofset 2 (2012): 5-10.

5. Liu Q., et al. "Is shift work associated with a higher risk of overweight or obesity? A systematic review of observational studies with meta-analysis". International Journal of Epidemiology 47.6 (2018): 1956-1971.

6. Langenberg D., et al. "Diet, physical activity, and daylight exposure patterns in night-shift workers and day workers". Annals of Work Exposures and Health 63.1 (2019): 9-21.

7. Saulle R., et al. "Shift work, overweight and obesity in health professionals: a systematic review and meta-analysis". La Clinica Terapeutica 169.4 (2018): e189-e197.

8. Souza RV., et al. "The effect of shift work on eating habits: a systematic review". Scandinavian Journal of Work, Environment and Health 45.1 (2019): 7-21.

9. Sweeney E., et al. "The relationship between anthropometric measures and cardiometabolic health in shift work: findings from the Atlantic PATH Cohort Study". International Archives of Occupational and Environmental Health 93.1 (2020): 67-76.

10. Wyse CA., et al. "Adverse metabolic and mental health outcomes associated with shiftwork in a population-based study of 277,168 workers in UK biobank". Annals of Medicine 49.5 (2017): 411-420.

11. Kubo T., et al. "Retrospective cohort study of the risk of obesity among shift workers: findings from the Industry-based Shift Workers' Health study, Japan". Occupational and Environmental Medicine 68.5 (2011): 327-331.
12. Correia FGS., et al. "Night work is related to higher global and central adiposity in Brazil: National Health Survey, 2013". American Journal of Industrial Medicine 63.1 (2020): 85-91.

13. Çakmak G and Kızıl M. "Vardiyalı çalışan işçilerde beslenme durumu, uyku kalitesi ve metabolik sendrom arasındaki ilişki". Beslenme ve Diyet Dergisi 46.3 (2018): 266-275.

14. James SM., et al. "Shift Work: disrupted circadian rhythms and sleep-implications for health and well-being". Current Sleep Medicine Reports 3.2 (2017): 104-112.

15. Lin PC., et al. "Atypical work schedules are associated with poor sleep quality and mental health in Taiwan female nurses". International Archives of Occupational and Environmental Health 85.8 (2012): 877-884.

16. Fekedulegn D., et al. "Shift work and sleep quality among urban police officers: the BCOPS study". Journal of Occupational and Environmental Medicine 58.3 (2016): e66-e71.

17. Lim YC., et al. "Association between night-shift work, sleep quality and metabolic syndrome". Occupational and Environmental Medicine 75.10 (2018): 716-723.

18. Dai C., et al. "The effect of night shift on sleep quality and depressive symptoms among Chinese nurses". Neuropsychiatric Disease and Treatment 15 (2019): 435-440.

19. Torquati L., et al. "Shift work and poor mental health: a metaanalysis of longitudinal studies". American Journal of Public Health 109.11 (2019): e13-e20.

20. Lee A., et al. "Night shift work and risk of depression: metaanalysis of observational studies". Journal of Korean Medical Science 32.7 (2017): 1091-1096.

21. Report of a Joint FAO/WHO/UNU Expert Consultation. "Human energy requirements". FAO Food and Nutrition Technical Report Series 1 (2004).

22. World Health Organization. "Body mass index-BMI".

23. World Health Organization. "Waist circumference and waistto-hip ratio: Report of a WHO Expert Consultation" (2011). 
24. Ashwell M and Gibson S. "Waist-to-height ratio as an indicator of 'early health risk': simpler and more predictive than using a 'matrix' based on BMI and waist circumference". BMJ Open 6.3 (2016): e010159.

25. Ben-Noun L., et al. "Neck circumference as a simple screening measure for identifying overweight and obese patients". Obesity Research 9.8 (2001): 470-477.

26. Buysse DJ., et al. "The pittsburgh sleep quality index: a new instrument for psychiatric practice and research". Psychiatry Research 28.2 (1989): 193-213.

27. Ağargün MY., et al. "Pittsburgh uyku kalitesi indeksinin geçerliği ve güvenirliği”. Türk Psikiyatri Dergisi 7.2 (1996): 107-115.

28. Zigmond AS and Snaith RP. "The hospital anxiety and depression scale". Acta Psychiatrica Scandinavica 67.6 (1983): 361370.

29. Aydemir Ö., et al. "Hastane anksiyete ve depresyon ölçeği Türkçe formunun geçerlilik ve güvenilirliği”. Türk Psikiyatri Dergisi 8.4 (1997): 280-287.

30. Kazemi M., et al. "Assessing the effect of shift work among petrochemical Industries staff at Mahshahr, Iran". Journal of Paramedical Sciences 8.4 (2017): 36-43.

31. Grundy A., et al. "Rotating shift work associated with obesity in men from northeastern Ontario". Health Promotion and Chronic Disease Prevention in Canada Research, Policy and Practice 37.8 (2017): 238-247.

32. Bracci M., et al. "Nocturnin gene diurnal variation in healthy volunteers and expression levels in shift workers". BioMed Research International 1 (2019): 1-8.

33. Buchvold HV., et al. "Associations between night work and BMI, alcohol, smoking, caffeine and exercise - a cross-sectional study". BMC Public Health 15.1112 (2015).

34. Samhat Z., et al. "Relationship between night shift work, eating habits and BMI among nurses in Lebanon". BMC Nursing 19.25 (2020).
35. Peplonska B., et al. "Association of Rotating Night Shift Work with BMI and Abdominal Obesity among Nurses and Midwives". Plos One 10.7 (2015): e0133761.

36. Kim MJ., et al. "Association between shift work and obesity among female nurses: Korean Nurses' Survey". BMC Public Health 13.1204 (2013).

37. Griep RH., et al. "Years worked at night and body mass index among registered nurses from eighteen public hospitals in Rio de Janeiro, Brazil". BMC Health Services Research 14.603 (2014).

38. Flahr H., et al. "A systematic review of physical activity-based interventions in shift workers". Preventive Medicine Reports 10 (2018): 323-331.

39. Brum MCB., et al. "Night shift work, short sleep and obesity". Diabetology and Metabolic Syndrome 12.13 (2020).

40. Ko SB. "Night shift work, sleep quality, and obesity". Journal of Lifestyle Medicine 3.2 (2013): 110-116.

41. Gildner TE., et al. "Sleep duration, sleep quality, and obesity risk among older adults from six middle-income countries: findings from the study on global AGEing and adult health (SAGE)". American Journal of Human Biology 26.6 (2014): 803812.

42. Abbasi M., et al. "Factors affecting sleep quality in firefighters". Sleep and Hypnosis 20.4 (2018): 283-289.

43. Beebe D., et al. "Diet quality and sleep quality among day and night shift nurses". Journal of Nursing Management 25.7 (2017): 549-557.

44. Rahe C., et al. "Associations between poor sleep quality and different measures of obesity". Sleep Medicine 16.10 (2015): 1225-1228.

45. Jennings JR., et al. "Self-reported sleep quality is associated with the metabolic syndrome". Sleep 30.2 (2007): 219-223.

46. Catırtan H and Bakır BO. "Comparison of sleep quality, waist circumference and body mass index among shift and non-shift workers". Journal of Turkish Sleep Medicine 5.2 (2018):40-45. 
47. Zeng LN., et al. "Prevalence of poor sleep quality in nursing staff: a meta-analysis of observational studies". Behavioral Sleep Medicine (2019): 1-14.

48. Demiral Y., et al. "Üniversite hastanesinde çalışan hekimlerde iş doyumunun anksiyete ve depresyon düzeylerine etkisi". Dokuz Eylül Üniversitesi Tıp Fakültesi Dergisi 20.3 (2006): 157164.

49. Saracoğlu GV., et al. "Frequency of daytime sleepiness and risk of anxiety and depression among shift workers in two selective factories". Turkish Journal of Public Health 13.3 (2015): 206-216.

50. Sharafi SE., et al. "Prevalence of anxiety and depression in patients with overweight and obesity". Obesity Medicine 17.100169 (2020).

51. Speed MS., et al. "Investigating the association between body fat and depression via mendelian randomization". Translational Psychiatry 9.184 (2019).

52. Guedes EP., et al. "Body composition and depressive/anxiety symptoms in overweight and obese individuals with metabolic syndrome". Diabetology and Metabolic Syndrome 5.82 (2013).

\section{Assets from publication with us}

- Prompt Acknowledgement after receiving the article

- Thorough Double blinded peer review

- Rapid Publication

- Issue of Publication Certificate

- High visibility of your Published work

Website: www.actascientific.com/

Submit Article: www.actascientific.com/submission.php

Email us: editor@actascientific.com

Contact us: +919182824667 